\title{
Application of a Channel Model for Describing Propagation of Tsunami-Like Single Waves in a Channel with Variable Cross-Section
}

\author{
A.Yu. Bazykina, S.F. Dotsenko \\ Marine Hydrophysical Institute, Russian Academy of Sciences, Sevastopol, \\ Russian Federation \\ e-mail: sf_dotsenko@mail.ru
}

\begin{abstract}
Being seismically active, the Bosporus area is always under the possibility of tremors. The earthquake with a magnitude of more than 5 , which caused a tsunami wave, has already been observed in this region. Therefore, there is a need to study the amplitude characteristics of the waves as they propagate in the strait. Channel model of surface long waves is used to describe propagation of single linear waves in the channel of variable cross-section simulating the Bosporus. Numerical analysis is done both for the maximum height and wave velocity of the waves propagating from the Sea of Marmara to the Black Sea and vice versa, and for the case of evolution of the initial fluid displacement at its various location in the strait. Growth of a wave height and velocity is correlated with decrease of the strait width and its cross-sections' areas. When the waves propagate from the Black Sea to the Marmara their intensification is more significant than that at their movement in the opposite direction. Wave speed can be comparable or even exceed the value of the velocity of the background flow in the Bosporus. In the case when the waves propagate from the tsunami generation zone in the strait middle part, the highest rises of the fluid free surface do not exceed the absolute value of the sea surface initial displacement.
\end{abstract}

Keywords: tsunami waves, the Bosporus Strait, channel theory of long waves, numerical solutions, wave propagation in a strait, wave intensification.

DOI: 10.22449/1573-160X-2015-1-27-38

(C) 2015, A.Yu. Bazykina, S.F. Dotsenko

(C) 2015, Physical Oceanography

Introduction. Strait is a water body between the two land masses that connects the adjacent water bodies or their parts and is used for navigation. As a rule, the Straits and the adjacent basins are areas of intense currents and wave processes, suggesting the need for a comprehensive study of the water dynamics in such regions of the ocean where navigation is associated with considerable risk.

Zone of the Bosporus Strait is a place of collision of two continental plates. It is seismically active and there is always the possibility of tremors. That is why the danger of a tsunami here should not be ignored. Such waves can be caused by the earthquakes occurring both underwater and overland. Article [1] shows a map of historical earthquakes in the Black Sea region and its surroundings which occurred before 1900. It also shows magnitude 5 and more earthquakes to observe in the Bosporus area.

So, the tsunami accompanied by a wave height of $2-3 \mathrm{~m}$ [2] was observed in the Bosporus in 557.

Due to the compact planning of the coast, ongoing business activities and the existence of the seaside recreation areas a 0.5 meters high tsunami can have disastrous consequences. Therefore, the need for a detailed research of the possible maximum height of these waves increases.

PHYSICAL OCEANOGRAPHY NO. 1 (2015) 
In this article we consider the propagation of surface long waves in the channel simulating the Bosporus. Changes in the propagation characteristics of the waves from the Black Sea to the Marmara and vice versa is analyzed. To describe the evolution of linear long waves in the strait channel theory is applied. In this theory as the main variables averaged across the free surface channel mirror displacement and the mean horizontal velocity of current in the strait cross section are used [3, 4].

Channel theory of long waves found its application in the tidal theory [5, 6], the description of the propagation of a tsunami-type waves in the variable section channels [7], tidal waters in the estuaries [8], surface [9] and internal (two-layer fluid) [10] seiches, etc. Doubtless advantage of channel theory of waves is the replacement of the two-dimensional problem by the one-dimensional one.

Mathematical formulation of the problem. In $O x_{1} y_{1}$ horizontal plane $\left(x_{1}, y_{1}-\right.$ Cartesian coordinates of the point in the plane) the curved channel (Fig. 1) is considered having cross-section $S=S(x)$ and mirror width $b=b(x)$ constantly varying along the channel axis in accordance with the accepted laws, where $x-\mathrm{a}$ curvilinear coordinate along the middle line of the channel. Through $H=H(x)$ we denote the maximum depth of the channel in its cross-section at the $x$ point.

In the linear approximation, we consider two versions of the problem of the wave propagation in a strait: problem I - single wave propagation along the strait from the $x=0$ (the Sea of Marmara) point and leaving it at the opposite end, designated as the $x=$ of $L$ (the Black Sea) point; problem II - propagation of a single wave entering the strait in the $x=$ of $L$ (the Black Sea) point and leaving it at the other end at the $x=0$ (the Sea of Marmara) point; task III - evolution of a single initial fluid free surface displacement in the central part of the strait.

To describe the propagation of surface waves we apply the channel theory of long waves [3, 4]. It is a one-dimensional approximation of the model of long waves and operates the averaged over the cross section of the channel horizontal velocity $u=u(x, t)(t-$ time $)$ and averaged across the cross-section of the strait mirror along the coordinate $y$ by the fluid free surface displacement $\zeta=\zeta(x, t)$.

Under this approach, the linear motion of the fluid in the channel is described by the following system of two equations

$$
\frac{\partial u}{\partial t}=-g \frac{\partial \zeta}{\partial x}, \frac{\partial \zeta}{\partial t}+\frac{1}{b} \frac{\partial(S u)}{\partial x}=0,
$$

where $g$ is free fall acceleration. Excluding the longitudinal velocity $u$ of the system (1) leads to a one-dimensional wave equation with coefficients dependent from the $x$ :

$$
\frac{\partial^{2} \zeta}{\partial t^{2}}-\frac{g}{b} \frac{\partial}{\partial x}\left(S \frac{\partial \zeta}{\partial x}\right)=0
$$

The value

$$
C(x)=\sqrt{\frac{g S(x)}{b(x)}}
$$

It acts as a local long-wave propagation velocity in the with variable cross-section channel. 
The initial conditions for the system of equations (1) require the specification of fields $u$ and $\zeta$ at the initial time $t=0$. We assume that at $t=0$, the fluid in the channel for the problems I and II is located in a perturbed state, i.e.

$$
u(x, 0)=\zeta(x, 0)=0,
$$

And for the problem III it is unperturbed but stationary, i.e.

$$
u(x, 0)=0, \quad \zeta(x, 0)=\zeta_{0}(x) .
$$

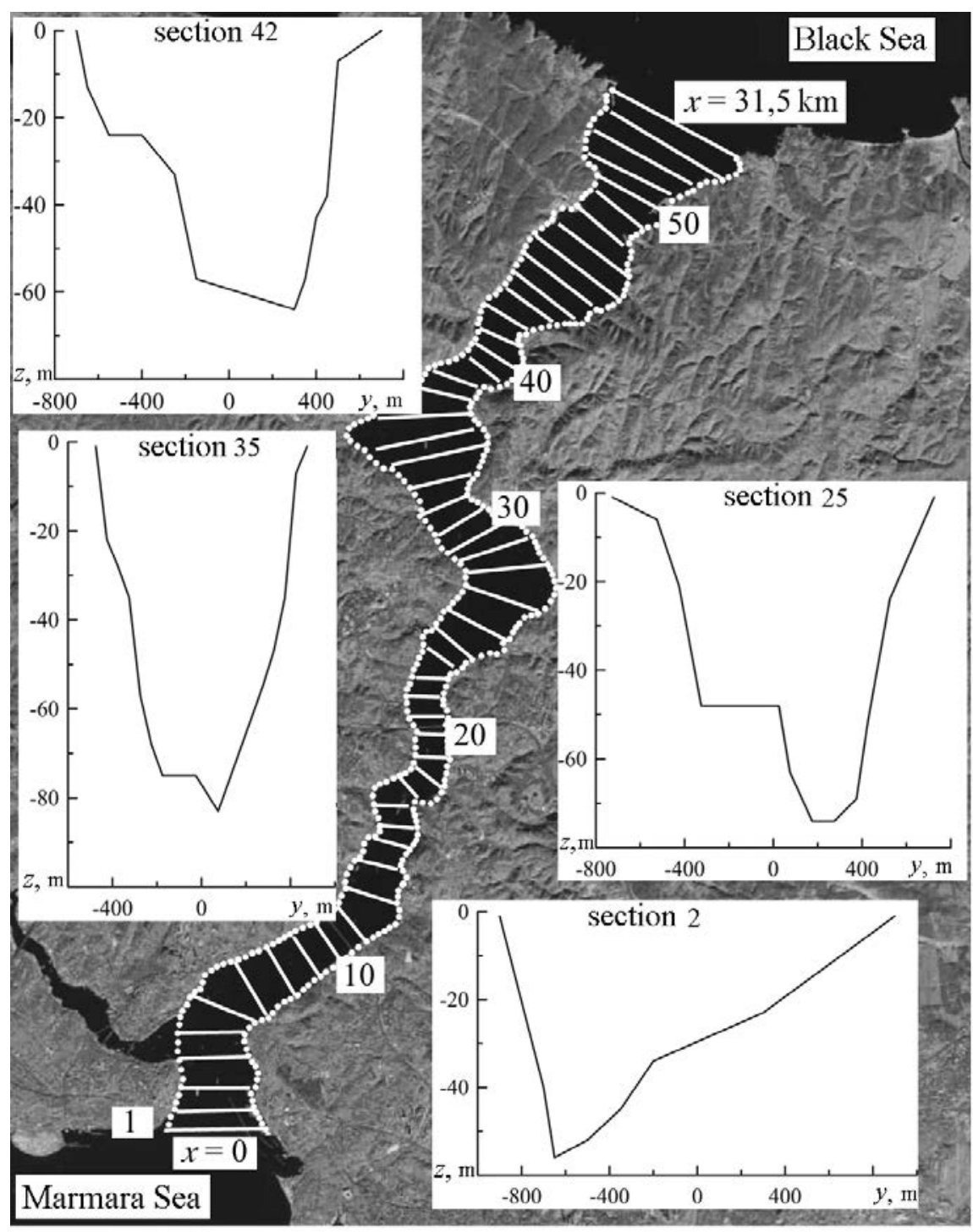

Fig. 1. The Bosporus with an indication of the positions of 54 cross-sections and the depth distributions (on the sidebar) in sections 2, 25, 35 and 42 
The aforementioned problems I, II and III have different specification of the boundary conditions on the straight ends, namely the problem I simulate a singlewave entrance into the strait through the left boundary, if you specify:

$$
\begin{gathered}
\zeta=a_{0} \sin \left(\pi \tau_{1}\right), \quad u=\sqrt{\frac{g b}{S}} \zeta \quad\left(x=0,0 \leq t \leq T_{1}\right), \\
\frac{\partial u}{\partial t}-C_{0} \frac{\partial u}{\partial x}=0\left(x=0, t>T_{1}\right), \\
\frac{\partial u}{\partial t}+C_{1} \frac{\partial u}{\partial x}=0(x=L, t \geq 0),
\end{gathered}
$$

where $a_{0}$ is the maximum initial fluid free surface displacement; $\tau_{1}=\frac{t}{T_{1}} ; C_{0}=$ $=C(0) ; C_{1}=C(L) ; T_{1}=\lambda / C_{0}, \lambda$ is initial width of wave.

In the problem II the boundary conditions simulate the entrance of a single wave in the strait through the right border, provided:

$$
\begin{gathered}
\zeta=a_{0} \sin \left(\pi \tau_{2}\right), \quad u=-\sqrt{\frac{g b}{S}} \zeta \quad\left(x=L, 0 \leq t \leq T_{2}\right), \\
\frac{\partial u}{\partial t}+C_{1} \frac{\partial u}{\partial x}=0\left(x=L, t>T_{2}\right), \\
\frac{\partial u}{\partial t}-C_{0} \frac{\partial u}{\partial x}=0(x=0, t \geq 0),
\end{gathered}
$$

where $\tau_{2}=\frac{t}{T_{2}} ; T_{2}=\lambda / C_{1}$.

In the problem III the free surface form at the initial time is specified as a single individual character displacement entirely located in the strait, and the conditions at the strait ends simulate a free exit of the waves:

$$
\begin{gathered}
\zeta=a_{0} \cos ^{2}\left(\frac{\pi\left(x-x_{0}\right)}{\lambda}\right)\left(t=0,0 \leq x \leq L,\left|x-x_{0}\right| \leq \frac{1}{2} \lambda\right), \\
\frac{\partial u}{\partial t}-C_{0} \frac{\partial u}{\partial x}=0 \quad(x=0, t \geq 0), \\
\frac{\partial u}{\partial t}+C_{1} \frac{\partial u}{\partial x}=0 \quad(x=L, t \geq 0) .
\end{gathered}
$$

Initial fluid displacement field parameters must satisfy the condition $\lambda / 2 \leq x_{0} \leq L-\lambda / 2$ that ensures the location of primary fluid perturbations in the strait zone.

All three of the initial-boundary value problems, namely the problem I, including the system of equations (1) and the boundary conditions (5) - (7), the problem II, which includes the equations (1) and the boundary conditions (8) (10), and the problem III, including a system of equations (1), the initial conditions (4), (11) and the boundary conditions (12), (13) were solved numerically by finite 
difference method for explicit-implicit scheme at the half-step shifted along the $x$ coordinate relatively to each other uniform grids for the fields $u$ and $\zeta$ [11].

Length of the strait, connecting the Black and Marmara seas, $L=31.5 \mathrm{~km}$, its maximum width $-3600 \mathrm{~m}$ (in the north), the smallest width $-790 \mathrm{~m}$, the depth of the channel - from 33 to $80 \mathrm{~m}$. In the Bosporus there is a two-layer current, consisting of a sweetened water flow in the upper layer from the Black Sea to the Marmara, moving southward at the velocity of $1.5-2 \mathrm{~m} \cdot \mathrm{s}^{-1}$, and the salt-water lower current from the Marmara to the Black sea, having the velocity of 0.9 $1 \mathrm{~m} \cdot \mathrm{s}^{-1}$. Salt-water current continues in the Black Sea as underflow.

54 cross-sections along the $x$-axis are used to specify the geometry of the strait. Depth distributions in some of them are shown in the sidebars in Fig. 1. In accordance with the shape of the cross-sections the local mirror width of the Strait mirrors $b(x)$. Cross-sectional areas $S(x)$, included in the system of long-wave equations (1), were calculated by the method of trapezoids. To determine the strait parameters at the intermediate points, linear interpolation was carried out.

Fig. 2 shows obtained by the aforementioned method the piecewise-line distributions of the strait maximum depth $H(x)$ (Fig. 2, a), the half-width strait mirror $b(x) / 2$ (Fig. 2, $b$ ) and the cross-sectional area $S(x)$ (Fig. 2, $c$ ). The entrance to the Bosporus from the Marmara Sea corresponds to the point $x=0$, the exit from the strait to the Black Sea - to the point $x=L$. The changes of geometric parameters along the strait are heterogeneous and are characterized by areas of increase and decrease.
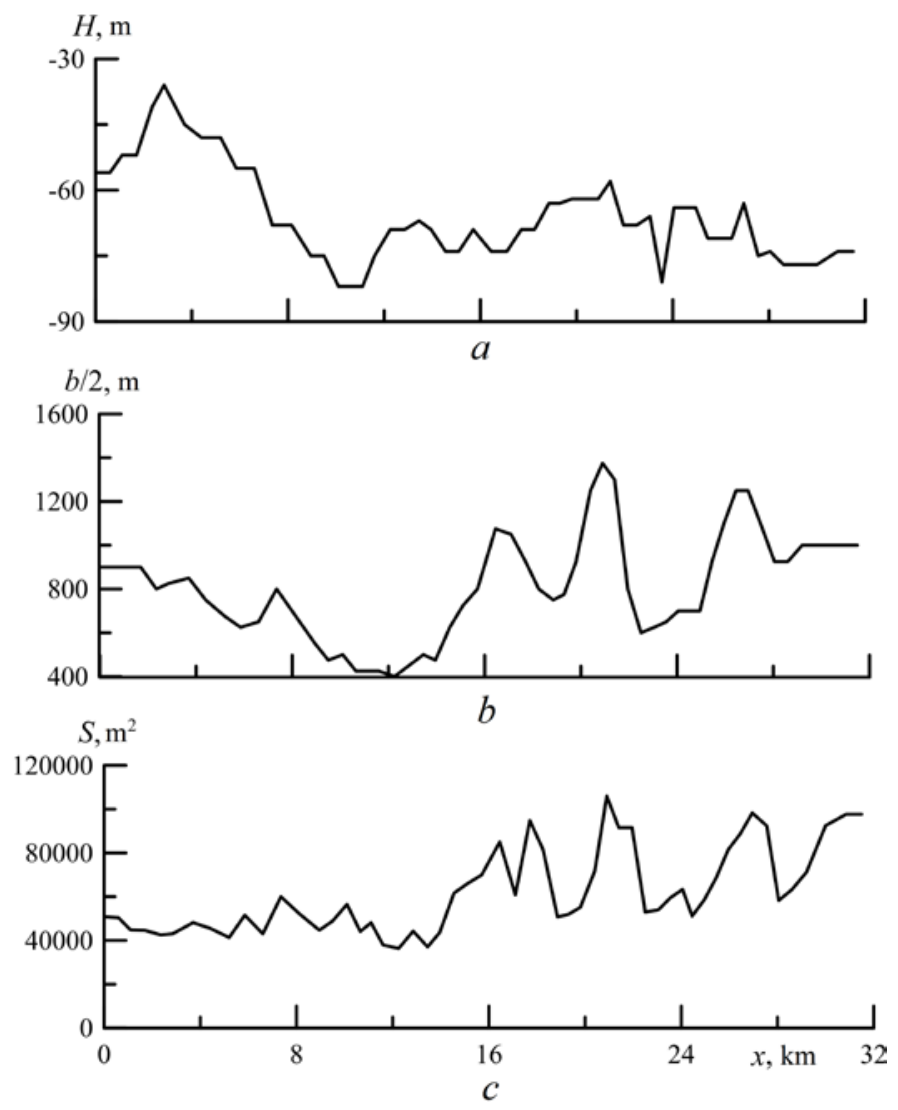

Fig. 2. Distributions along the Bosporus axis of the maximum depth $(a)$, mirror half-width $(b)$ and cross-section areas $(c)$ 
In the finite-difference algorithm numerical implementation the uniform grid with 5,000 - 10,000 steps along the $x$ coordinate and with a time step $t$ up to $0.1 \mathrm{~s}$ is applied.

Distribution of a single wave from the Marmara to the Black Sea and vice versa. A single wave that entered the strait from the Sea of Marmara, is distributed with $C(x)$ local variable velocity, changing its height (Fig. 3).
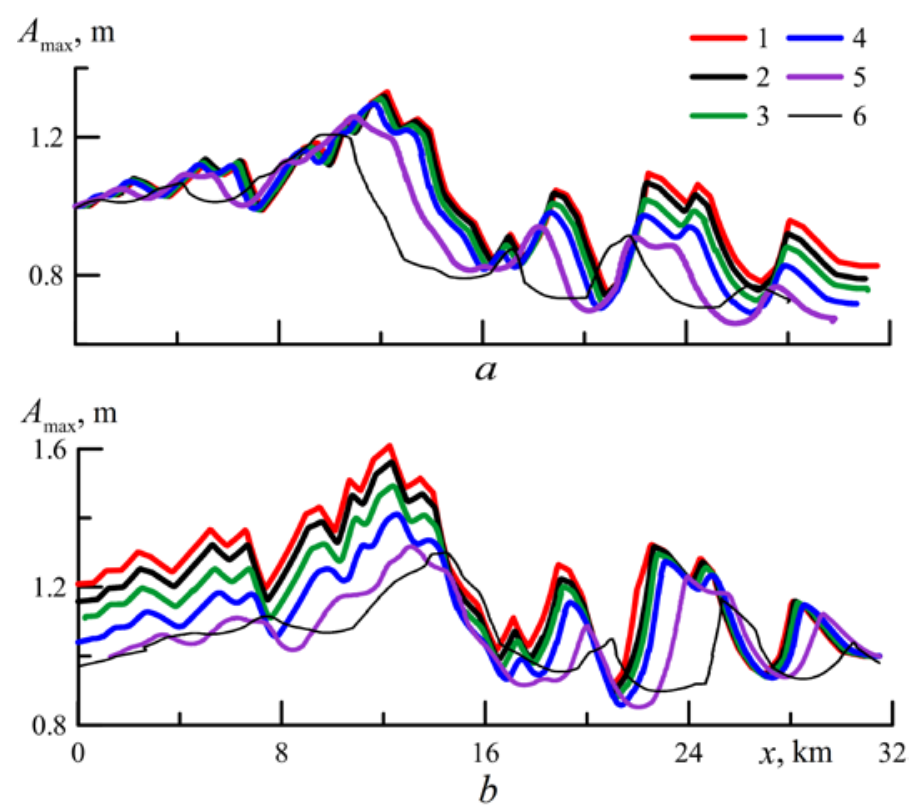

Fig. 3. The change along the strait axis of the maximum possible heights of waves propagating from the Marmara to the Black Sea (a) and from the Black Sea to the Marmara $(b)$ at various initial wavelengths: 1 - calculation according to the approximate formula below (18); $2-\lambda=0.5 \mathrm{~km}$; $3-\lambda=1 \mathrm{~km} ; 4-\lambda=2 \mathrm{~km} ; 5-\lambda=5 \mathrm{~km} ; 6-\lambda=10 \mathrm{~km}$ (initial wave height is $1 \mathrm{~m}$ )

For all the $t>0$ numerically obtained distributions along the strait of the maximum possible heights of the surface waves are shown in Fig. 3, $a$ for the five values of the initial wave length entering the strait. Note that the original wavelength is defined as the width of the initial fluid displacement at the height of $1 / 3 a_{0}$. As follows from this Figure, the distribution of wave heights depends on the initial wavelength, i.e. in fact the relationship between the wavelength $\lambda$ and the characteristic scale of changes in the geometric parameters in the strait. The trend of increase of the overall maximum heights of waves in the strait with the decreasing of length. In the separate parts there is 1.3 times increase in wave height. As a rule, local intensification of long waves is associated with a local decrease of the strait width and its cross-sectional area.

A similar relationship of wave heights and the local geometry of the crosssections is manifested in the channels for the time-harmonic waves [12]. The longer the wave is, the less significant is the influence of the strait shape changes on it, although in general for all five wavelength values the change of wave heights along the $x$ coordinate is qualitatively the same. 
We also consider the change in the maximum height of a long wave propagating in the strait from the Black Sea to the Marmara. For five wavelength values at the entrance to the strait (the Black Sea) the distributions of the maximum wave heights along the strait are shown in Fig. 3, $b$. They depend on the length of the wave entering it. As in the previous case, an increase in the maximum possible wave heights with decreasing length is observed. In some parts of the strait there is 1.5 times increase in the height.

It is interesting to consider the propagation of sufficiently short compared to the heterogeneities of the strait cross sections of surface waves (but the long ones in terms of the theory of long wave processes). This approach in respect to the variable rectangular-section channels is described, for example, in [13].

For a rectangular-section channel $S(x)=b(x) H(x)$ the equation (2) is as follows

$$
\frac{\partial^{2} \zeta}{\partial t^{2}}-g\left(\frac{d H}{d x}+\frac{H}{b} \frac{d b}{d x}\right) \frac{\partial \zeta}{\partial x}-g H \frac{\partial^{2} \zeta}{\partial x^{2}}=0 .
$$

To convert the equation (14) to the differential equation with constant coefficients we perform the change of the desired function by the following formula

$$
\zeta(x, t)=A(x) \Phi[t, \theta(x)],
$$

where $A(x), \Phi[t, \theta], \theta(x)$ are unknown functions. Substituting the relationship (15) into equation (14) we obtain the following

$$
\begin{gathered}
A \frac{\partial^{2} \Phi}{\partial t^{2}}-g\left(\frac{d H}{d x}+\frac{H}{b} \frac{d b}{d x}\right)\left(\Phi \frac{d A}{d x}+A \frac{\partial \Phi}{\partial \theta} \frac{d \theta}{d x}\right)= \\
=g H\left[\Phi \frac{d^{2} A}{d x^{2}}+2 \frac{d A}{d x} \frac{\partial \Phi}{\partial \theta} \frac{d \theta}{d x}+A \frac{\partial \Phi}{\partial \theta} \frac{d^{2} \theta}{d x^{2}}+A \frac{\partial^{2} \Phi}{\partial \theta^{2}}\left(\frac{d \theta}{d x}\right)^{2}\right] .
\end{gathered}
$$

This equation comes to the wave equation with constant coefficients in the performance of the three differential relations [13]:

$$
\begin{gathered}
\frac{d^{2} A}{d x^{2}}+\frac{1}{H b} \frac{d(H b)}{d x} \frac{d A}{d x}=0, \\
2 H b \frac{d \theta}{d x} \frac{d A}{d x}+\frac{d}{d x}\left(H b \frac{d \theta}{d x}\right) A=0, \\
g H\left(\frac{d \theta}{d x}\right)^{2}=1 .
\end{gathered}
$$

Having integrated the equation (16) in accordance to $x$, taking into account the one-dimensional eikonal equation (17), we obtain the conservation law (Green's law $[3,5])$ :

$$
A H^{\frac{1}{4}} b^{\frac{1}{2}}=\text { const. }
$$

For the rectangular-section channel and the waves propagating from the Marmara to the Black Sea, this law can be written as follows 


$$
A(x)=A(0)\left[\frac{b(0)}{b(x)} \frac{S(0)}{S(x)}\right]^{\frac{1}{4}} .
$$

A similar relationship holds for the waves propagating from the Black Sea to the Marmara. Knowing the law of wave height variation (18), it is possible by means of the first of the equations of long waves (1) to find an approximate expression for the amplitude of the wave velocity in the case of waves (15) in a channel with slowly varying cross-sectional geometry:

$$
U(x) \approx \pm \frac{g}{C} A(x) .
$$

In Fig. 3 the calculated curves $2-6$ are supplemented by the relationships (18) for the maximum heights of long waves propagating from the Marmara to the Black Sea and vice versa. Distributions of the heights of waves $A_{\max }$ along the strait in case of relatively short wavelengths $(0.5$ and $1 \mathrm{~km})$ differ a little from those calculated under the analytical formula (18), regardless of the wave propagation direction. At longer wavelengths, this difference becomes more significant. Note that the difference in wave heights distributions increases with the distance traveled by the waves from the entry point into the strait. Heights of longer surface waves are less sensitive to changes in the geometric parameters of the strait. In general, the greatest heights of the waves occur in the parts of the strait with the smallest width and cross-sectional area.
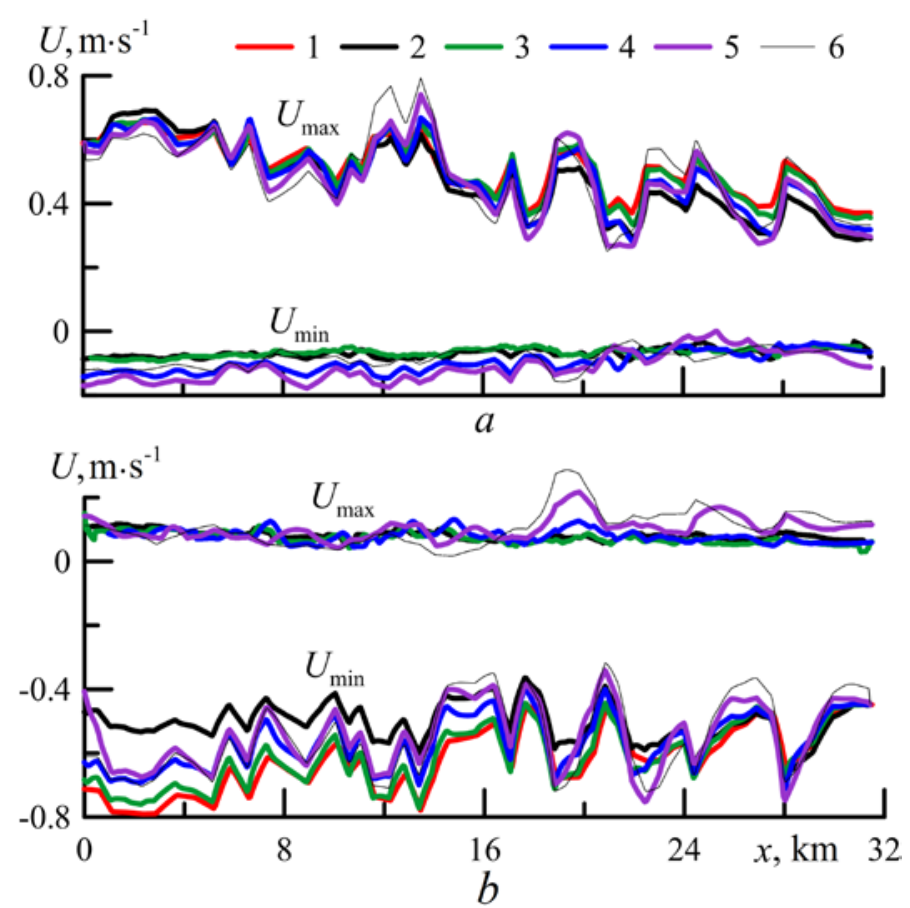

Fig. 4. Change along the strait axis of the maximum $U_{\max }$ and the minimum $U_{\min }$ possible horizontal velocities in the waves propagating from the Marmara to the Black Sea (a) and from the Black Sea to the Marmara $(b)$ for different lengths of the entering wave: 1 - calculation under the approximate formula (19); $2-\lambda=0.5 \mathrm{~km} ; 3-\lambda=1 \mathrm{~km} ; 4-\lambda=2 \mathrm{~km} ; 5-\lambda=5 \mathrm{~km} ; 6-\lambda=10 \mathrm{~km}$ (initial wave height is $1 \mathrm{~m}$ ) 
Also, numerical calculations of changes along the strait of the maximum and minimum horizontal velocity cross-sections averages are carried out. In the propagation of waves from the Marmara to the Black Sea the positive direction wave current prevails (Fig. 4, a). If a wave enters the channel from the Black Sea, the wave velocity sign is reversed (Fig. $4, b$ ). For relatively short wavelengths $(0.5-1 \mathrm{~km})$ velocity distribution along the strait is described by the approximate formula (19), which allows estimating the maximum wave velocity for the waves propagating from the Marmara to the Black Sea, and the minimum wave velocity for the waves propagating from the Black Sea to Marmara.

We should note that the wave velocities according to their magnitude such that they can significantly increase or decrease the main current velocity. This effect increases with increasing of the height of the wave entering the Strait, and can lead to fundamental changes in the direction of background current.

It is interesting to analyze the possible intensification of the wave as a result of its coming through the strait from one sea basin to another. Fig. 5 shows the wave height relations obtained numerically at the exit from the strait to the Marmara $\left(A_{\max }(0)\right)$ or the Black Sea $\left(A_{\max }(L)\right)$ for wavelengths in the range of $1-20 \mathrm{~km}$. When the waves are coming from the Black Sea to the Marmara there is a marked intensification of the waves than in the case of their propagation in the opposite direction. Nevertheless, the numerical calculations showed no significant gain or attenuation of surface waves after passing through the Bosporus Strait in any direction.

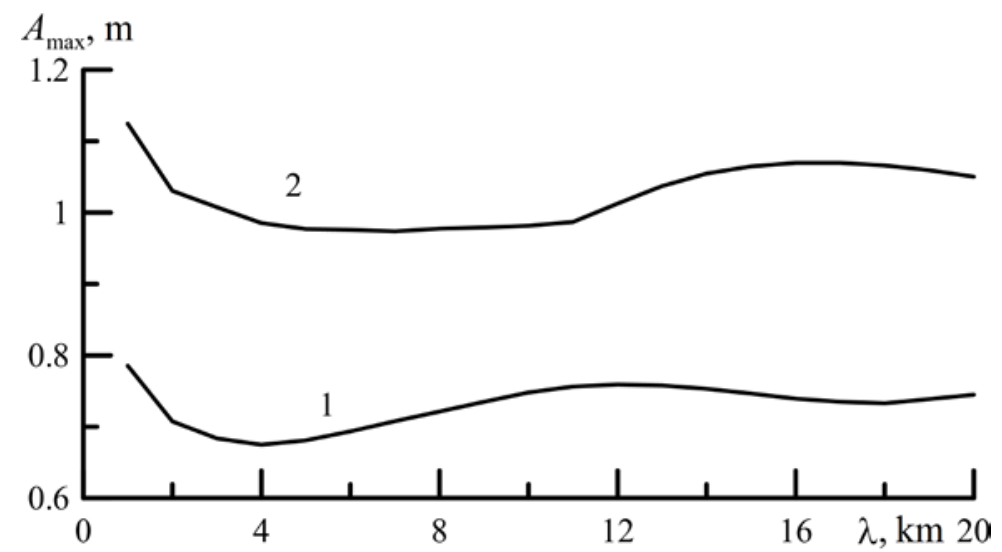

Fig. 5. Relationship of maximum wave heights on the extreme points of the strait from the length $\lambda$ of the wave entering the strait under its propagation from the Marmara to the Black Sea (1) and from the Black Sea to the Marmara (2) (initial wave height is $1 \mathrm{~m}$ )

The evolution of the local fluid free surface perturbations in the central part of the Bosporus Strait. We are to consider the evolution of the initial displacement of the fluid surface in the strait. This process is described in the problem III, including the equations (1) with the initial (4), (11) and boundary (12), (13) conditions. In the process of evolution the two waves are formed, extending in opposite directions from the area of the initial fluid perturbation. Due to changes in the geometric parameters of the strait there is a transformation of these waves, 
which depends on the width of the initial fluid perturbations and position of the generation zone in the strait. When waves reach the strait open borders, their free access to the Marmara and the Black Sea in accordance with the conditions (12) and (13) is observed.

Fig. 6 shows the distributions along the channel of the maximum possible rise of the free surface $(6, a)$, the maximum $(6, b)$ and minimum $(6, c)$ of horizontal velocity of the wave current in the Bosporus. The height of the initial rise of the level was specified equal to $1 \mathrm{~m}$, the width of the perturbation zone $-\lambda=5 ; 10 ; 15$; $20 \mathrm{~km}$. Computational experiments were carried out for a number of positions of the initial perturbation of fluid zones along the Bosporus. They showed that the during the displacement of the generation zone from the central part of the strait in the direction of the Black Sea the intensification of the waves entering in the Sea of Marmara was observed. On the contrary, during the displacement of the generation zone in the opposite direction the weakening of the waves at the Black Sea strait border took place.
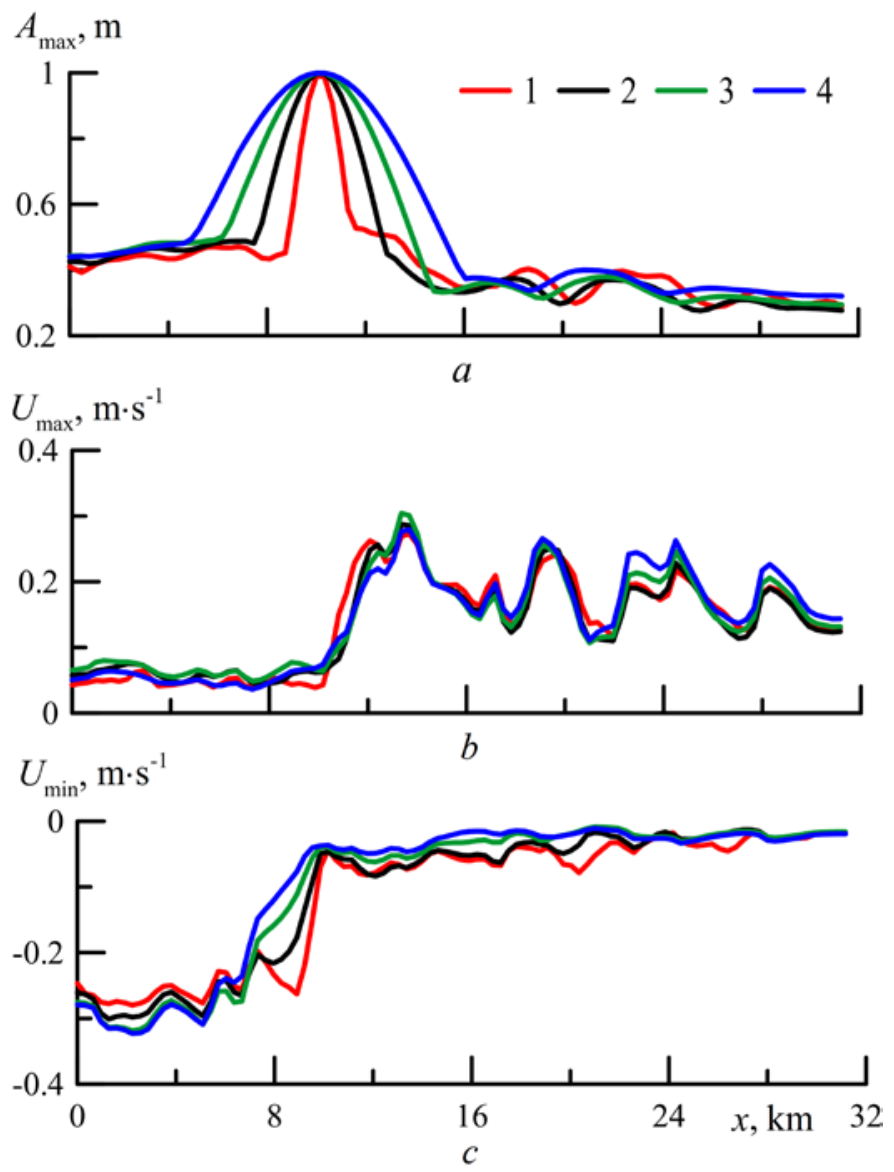

Fig. 6. Distribution along the strait axis of the maximum possible wave heights $(a)$, the maximum $(b)$ and minimum $(c)$ horizontal wave velocities in the evolution of single fluid surface rise having the width of 5, 10, 15 and $20 \mathrm{~km}$ (curves $1-4$, respectively) with center in $x_{0}=10 \mathrm{~km}$ (initial wave height is $1 \mathrm{~m}$ ) 
The maximum possible height of the tsunami waves are observed in the primary fluid perturbation area and tend to decrease moving away from the wave generating zone. Wave heights do not exceed the initial free surface of fluid displacement $a_{0}$. The smaller the width of the initial perturbation of the fluid in comparison with the spatial heterogeneity of the strait, the more the characteristics of waves react to changes in channel geometry. Due to the longitudinal heterogeneity of the strait the wave heights on the right and left of the generation zone are substantially determined by the geometry of the strait.

The wave velocity is alternating for the waves propagating in the opposite directions from the generation zone (Fig. 6, b, c). Under the initial liquid surface rise of $1 \mathrm{~m}$, for the cases shown in Fig. 6 , the wave velocity varies in the range $\left[-0.323 \mathrm{~m} \cdot \mathrm{s}^{-1}\right.$, $\left.0.304 \mathrm{~m} \cdot \mathrm{s}^{-1}\right]$.

Conclusion. The Sea of Marmara and the Black Sea are sea basins, where tsunami waves have been observed and are potentially possible [14, 15]. Although tsunami wave is not so frequent phenomenon in these seas, it is of high interest to evaluate its parameters in the strait during the propagation from the Marmara to the Black Sea and vice versa, as well as to evaluate the initial fluid surface displacement in the central part of the strait. These issues are considered within the framework of channel theory of long surface waves using numerical simulation techniques.

In the case of wave propagation from one sea basin to another, the distributions of the maximum possible wave heights in the strait are qualitatively similar and determined by its geometry changes. In the propagation of the single wave from the Marmara to the Black Sea its height 1.3 times increases, and during the passage of the wave from the Black Sea to the Marmara its height is 1.5 times greater than the initial value $a_{0}$. Increasing the wavelength in the strait, its maximum height decreases.

As for the horizontal wave current velocity, then the wave propagation of Marmara to the Black Sea (and from the Black Sea and Marmara), the maximum wave velocity can reach $0.79 \mathrm{~m} \cdot \mathrm{s}^{-1}\left(0.29 \mathrm{~m} \cdot \mathrm{s}^{-1}\right)$, the minimum is $0.18 \mathrm{~m} \cdot \mathrm{s}^{-1}$ $\left(0.75 \mathrm{~m} \cdot \mathrm{s}^{-1}\right)$ at the initial wave height $a_{0}=1 \mathrm{~m}$. That is, the wave velocity can be comparable or even exceed the velocity value of the background current in the strait.

In case of the propagation of tsunami-type waves caused by the initial fluid surface displacement, the characteristics of waves traveling in the Black Sea or the Marmara are different because of the asymmetry of longitudinal changes in the geometric parameters of the strait. The more intense the wave and the accompanying wave velocities are observed in the direction of the Sea of Marmara.

In general, the computational experiments did not reveal a significant increase in long surface waves for the Bosporus conditions. Typically, the height of waves in the strait does not exceed the initial free fluid surface of displacement $a_{0}$.

\section{REFERENCES}

1. Kalafat, D., 2003, “B.U. Kandilli Observatory and Earthquake Research Institute seismology laboratory”, CSEM EMSC, Newsletter, no. 19, pp. 5-7. 
2. Shnyukov, E.F., Mitin, L.I. \& Tsemko, V.P., 1994, "Katastrofy $v$ Chernom more [Catastrophes in the Black Sea]”, Kiev, Manuskript, 296 p. (in Russian).

3. Lamb, G. 1947, “Gidrodinamika [Hydrodynamics]”, Moscow, Leningrad, Gostekhizdat, 928 p. (in Russian).

4. Kochin, N.E, Kibel, I.A. \& Rose, N.V., 1963, “Teoreticheskaya gidromekhanika [Theoretical Fluid Mechanics]”, part 1, Moscow, Fizmatgiz, 584 p. (in Russian).

5. Shuleikin, V.V., 1968, "Fizika morya [Physics of the sea]", Moscow, Nauka, 1083 p. (in Russian).

6. Rzhonsnitsky, V.B., 1979, "Prilivnye dvizheniya [Tidal movements]”, Leningrad, Gidrometeoizdat, 244 p. (in Russian).

7. Cherkesov, L.V., 1973, "Poverkhnostnye i vnutrennie volny [Surface and Internal Waves]", Kiev, Naukova Dumka, 247 p. (in Russian).

8. Stoker, J. 1959, “Volny na vode [Water waves]”, Moscow, Inostrannaya literatura, 618 p. (in Russian).

9. Defant, A., 1961, “Physical oceanography”, Pergamon Press, vol. 1, 745 p.

10. Lemmin, U., Mortimer, C.H., 1986, “Tests of an extension to internal seiches of Defant's procedure for determination of surface seiche characteristics in real lakes”, Limnol. Oceanogr., vol. 31, no. 6, p. 1207-1231.

11. Voltsinger, N.E., Pyaskovsky, R.V., 1968, "Osnovnye okeanologicheskie zadachi teorii melkoy vody [Basic oceanographic problems in the theory of shallow water]", Leningrad, Gidrometeoizdat, 300 p. (in Russian).

12. Dotsenko, S.F., Rakova, I.N., 2012, "Rasprostranenie dlinnykh poverkhnostnykh voln v kanalakh peremennogo poperechnogo secheniya [The propagation of long surface waves in channels of variable cross-section]”, Morskoy gidrofizicheskiy zhurnal, no. 2, p. 3-17 (in Russian).

13. Didenkulova, I.I., Pelinovsky, D.E. \& Tyugin, D.Y. [et al.], 2012, “Begushchie dlinnye volny $v$ vodnykh pryamougol'nykh kanalakh peremennogo secheniya [The running long waves in the water rectangular channels of variable section]”, Vestnik MGOU, no. 5, p. 89-93 (in Russian).

14. Hébert, H., Schindelé, F. \& Altinok, Y. [et al.], 2005, “Tsunami hazard in the Marmara Sea (Turkey): numerical approach to discuss active faulting and impact on the Istanbul coastal areas”, Marine Geology, vol. 215, no. 1, p. 23-43.

15. Dotsenko, S.F., Ingerov, A.V. 2007, “Kharakteristiki chernomorskikh tsunami po dannym izmereniy [Characteristics of tsunami waves in the Black Sea according to the data of measurements]”, Morskoy gidrofizicheskiy zhurnal, no. 1, p. 21-31 (in Russian). 